\section{A Simple Endoscopic Technique for Replacement of a Permanent Malfunctioning Gastrostomy}

Percutaneous endoscopic gastrostomy (PEG) is a bedside procedure carried out under local anesthesia (1). PEG cannot be performed in conditions associated with esophageal obstruction (2). We describe here an endoscopic method for replacement of a permanent gastrostomy in a patient without an esophagus. The new gastrostomy was inserted via the preexisting gastrostomy tract.

A 73-year-old woman with a permanent feeding gastrostomy was referred to the hospital for evaluation of severe pericatheter leakage of gastric content. Twelve years earlier, she had accidentally swallowed her artifical dentures, which had caused severe lacerations of the middle and lower esophagus. She was operated on, and the esophagus was tied above the cardia and at the proximal end of the damaged esophageal segment. A permanent esophagostomy and Stamm's gastrosomy were performed. During the previous year, enlargement of the gastric opening around the tube had cause leakage of the gastric content through the gastrostomy tract. Repeated attempts to replace the gastrostomy tube with a large-bore catheter,

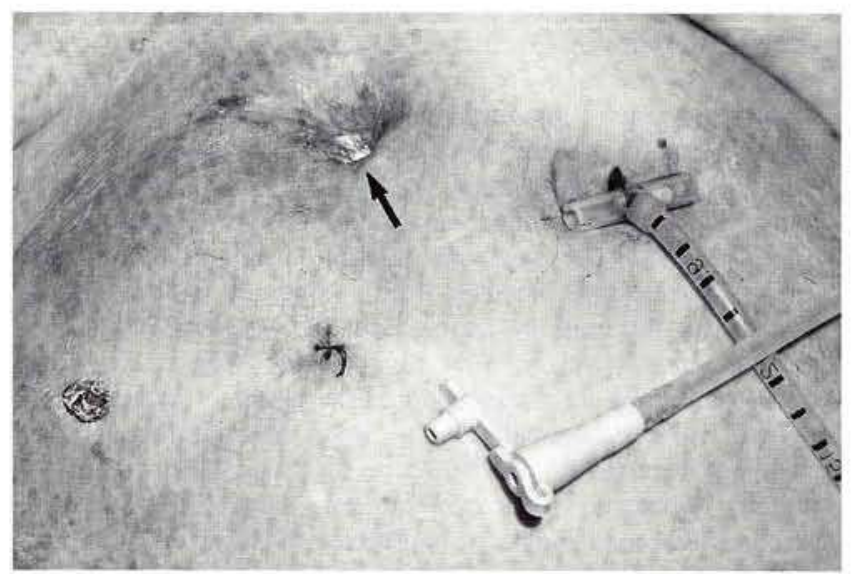

Figure 1: The patient after the installation of the new gastrostomy. The arrow points to the old gastrostomy orifice, serving as the insertion site for the endoscope. 
or to fixate it with Stomahesive, etc., failed. Endoscopic insertion of a duodenal feeding tube was also attempted without success.

Technique (Figure 1). The gastrostomy tube was removed, and the endoscope (Pentax video ED-3410) was introduced through the old stoma. The site of the puncture was visualized. The gastric and abdominal walls were pierced from the outside inward, and the new gastrostomy tube was inserted, as described previously (1). The endoscope was reintroduced to ensure proper placement of the gastrostomy.

There is only one report describing a nonsurgical technique for relocating a gastrostomy in a patient with an obstructed or non-existent esophagus. In this procedure, described by Gauderer (3), a large needle is blindly introduced through the old stomal opening. The gastric walls are pierced from the inside outward, and the new gastrostomy is inserted. The endoscopic technique we present here followed the same principle, inserting the new gastrostomy through the old stomal tract, but our procedure was performed under direct vision, and we therefore believe it is safer.
D. Lifshitz ${ }^{\text {I }}$, N. Arber ${ }^{2}$, M. Umnsky ${ }^{2}$, S. Lelcuk ${ }^{\text {I }}$, J. Rattan ${ }^{2}$

${ }^{1}$ Department of Surgery and ${ }^{2}$ Department of Gastroenterology, Ichilov Hospital-Sourasky Medical Center, Sackler Faculty of Medicine, Tel Aviv University, Tel Aviv, Israel

\section{References}

1. Gauderer $M W$, Ponsky JL, Izant RJ: Gastrostomy without laparotomy: a percutaneous endoscopic technique. J Pediatr Surg 1980; 15: 872-875.

2. Larson DE, Burten DD, Schroeder $K W$ : Percutaneous endoscopic gastrostomy: Indications, complications and mortality in 314 consecutive patients. Gastroenterology 1987; $93: 48-52$.

3. Gauderer $M W$ : A simple technique for correction of severe gastrostomy leakage. Surg Gynecol Obstet 1987; 165: 170-172.

Corresponding Author

J. Rattan, M.D., Department of Gastroenterology Ichilov Hospital, 6 Weizman St., 64239 Tel Aviv, Israel 